\title{
Experience of and factors associated with violence against sexual and gender minorities in nine African countries: a cross- sectional study
}

Alex Müller ${ }^{1,2^{*}}$ (D) Kristen Daskilewicz ${ }^{1}$, Mc Lean Kabwe ${ }^{3}$, Anna Mmolai-Chalmers ${ }^{4}$, Chelsea Morroni ${ }^{5}$, Nelson Muparamoto ${ }^{6}$, Adamson S. Muula ${ }^{7}$, Vincent Odira ${ }^{8}$, Martin Zimba ${ }^{9}$ and the Southern and Eastern African Research Collective for Health (SEARCH)

\begin{abstract}
Objective: The objective of this research was to assess physical and sexual violence experienced by sexual and gender minorities in nine African countries, and to examine factors associated with violence.

Methods: We conducted an exploratory multi-country cross-sectional study among self-identifying sexual and gender minorities, using a survey tool available in paper and online. Participants were sampled through venue-based and webbased convenience sampling. We analysed data using descriptive statistics and logistic regression, with Stata15.

Findings: Of 3798 participants, 23\% were gender minorities, 20\% were living with HIV, and 18\% had been coerced into marriage. Fifty-six per cent of all participants had experienced physical or sexual violence in their lifetime, and 29\% in the past year. Gender minorities had experienced significantly higher levels of violence compared to cisgender (sexual minority) participants. The variable most strongly associated with having experienced violence was being coerced into marriage (AOR, 3.02), followed by people living nearby knowing about one's sexual orientation and/or gender identity (AOR, 1.90) and living with HIV (AOR, 1.47).
\end{abstract}

Conclusion: Sexual and gender minorities in Eastern and Southern Africa experience high levels of violence. Sexual orientation and gender identity need to be recognised as risk factors for violence in national and regional law and policy frameworks. States should follow the African Commission Resolution 275 and provide protection against violence based on real or perceived sexual orientation or gender identity.

Keywords: Violence, Sexual and gender minority, Sexual orientation and gender identity and expression, Africa, Discrimination, Lesbian, Gay, Bisexual, Transgender, Intersex

\footnotetext{
* Correspondence: alex.muller@uct.ac.za

${ }^{1}$ Gender Health and Justice Research Unit, University of Cape Town, Cape Town, South Africa

${ }^{2}$ Department of Medical Ethics and History of Medicine, Universitätsmedizin Göttinge, Göttingen, Germany

Full list of author information is available at the end of the article
}

(c) The Author(s). 2021 Open Access This article is licensed under a Creative Commons Attribution 4.0 International License, which permits use, sharing, adaptation, distribution and reproduction in any medium or format, as long as you give appropriate credit to the original author(s) and the source, provide a link to the Creative Commons licence, and indicate if changes were made. The images or other third party material in this article are included in the article's Creative Commons licence, unless indicated otherwise in a credit line to the material. If material is not included in the article's Creative Commons licence and your intended use is not permitted by statutory regulation or exceeds the permitted use, you will need to obtain permission directly from the copyright holder. To view a copy of this licence, visit http://creativecommons.org/licenses/by/4.0/. The Creative Commons Public Domain Dedication waiver (http://creativecommons.org/publicdomain/zero/1.0/) applies to the data made available in this article, unless otherwise stated in a credit line to the data. 


\section{Background}

Violence against sexual and gender minorities is increasingly recognised as a key public health and human rights issue [1-5]. The United Nations (UN) Human Rights Council passed several resolutions to express concern about violence and discrimination against individuals motivated by their perceived or known sexual orientation and/or gender identity [6-9]. In 2014, the African Commission for Human and People's Rights (ACHPR) passed Resolution 275, which calls on African states to offer protection from violence based on real or perceived sexual orientation and gender identity, and outlines specific obligations to achieve this [10]. In 2016, the UN Human Rights Council appointed the first UN Independent Expert on Violence based on Sexual Orientation and Gender Identity [11], who, in a recent report ([12]:1), noted that:

"[Violence and discrimination against sexual and gender minorities] are committed in all corners of the world, and victims are presumed to be in the millions, every year. These acts extend from daily exclusion and discrimination to the most heinous acts, including torture and arbitrary killings. At their root lie the intent to punish the non-conformity of victims with preconceived notions of what should be their sexual orientation or gender identity."

Systematic reviews have demonstrated that sexual and gender minorities are more likely to be survivors of physical and sexual violence than the general population [2, 3]. A recent systematic review showed that the prevalence of violence against sexual and gender minorities that is motivated by bias against their sexual orientation and/or gender identity is also high [4]. However, the empirical studies included in these systematic reviews included little to no data from the African continent.

A joint dialogue of the African Commission for Human and People's Rights, the Inter-American Commission on Human Rights and the UN highlighted this data gap and concluded that: "[d] ata and evidence is critical to understand the extent and gravity of violations and to advocate for the adoption of measures to prevent, address and redress human rights violations faced by [sexual and gender minorities]" ([13]:19). In his most recent report, the UN Independent Expert highlighted the lack of empirical data on violence against sexual and gender minorities in contexts outside of the United States and Europe as one of the biggest challenges [12].

Our exploratory study aimed to provide data on the experience of, and factors associated with, violence against sexual and gender minorities in nine African countries.

\section{Methods}

\section{Study design and setting}

We conducted an exploratory cross-sectional study in nine countries: Botswana, eSwatini, Ethiopia, Kenya, Lesotho, Malawi, South Africa, Zambia and Zimbabwe. With the exception of Lesotho and South Africa (and Botswana since June 2019), these countries retain colonial-era laws that criminalise same-sex sexuality, although the implementation of these laws varies greatly from country to country [14]. Following the guidelines for research with sexual and gender minorities in rights-constrained environments [15], we worked as a partnership between an academic research team and local community-based organisations, all of whom were equal decision-making partners. We carefully considered the security risks, challenges and options for sampling sexual and gender minority populations [16, 17] and recruited participants through venue-based and online methods, using convenience sampling.

\section{Participants, eligibility and data collection}

Participants were eligible if they self-identified as a sexual and/or gender minority, were over the age of 18 and lived in one of the nine study countries. Data were collected with a phased approach, country per country, starting in countries with least risk (i.e., South Africa, eSwatini, Kenya), and ending in countries where data collection might pose the largest risks for data collectors and study participants (i.e., Ethiopia, Zambia). In each country, data were collected for 3 months. Overall, data collection took place between November 2016 and January 2019.

Due to safety and security concerns, we could not keep records of how many participants were approached. Overall, 4155 surveys were answered. Of those, 3798 surveys were included in the analysis. We excluded 357 surveys from our analysis: 67 due to protocol violations, and 290 due to incompleteness. These incomplete surveys only had data on participant characteristics, but no data on any of the outcomes (violence, mental health or health service use, see below). The participant characteristics of the excluded surveys showed no significant differences from the participant characteristics of included surveys.

\section{Measures}

The survey was available in the nine languages most widely spoken in the study countries (Amharic, Chichewa, English, isiNdebele, Sesotho, Setswana, Shona, Siswati, Swahili). A hard copy of the survey was used for community-based data collection. Seventy-five per cent of surveys $(n=2862)$ were filled out in hard copy, and $25 \%$ online $(n=936)$. Of the hard copy surveys, $76 \%(n=2170)$ were self-administered, and $24 \%(n=692)$ were filled out 
with the help of a fieldworker in cases where participants requested assistance. An online version of the survey was hosted on REDCap (Vanderbilt University, Nashville), and the link was distributed through community organisations and individuals. The survey itself and more information about its components are available in our previously published research report [18].

In consultation with our community partner organisations, we created composite categorical variables for both sexual orientation and gender identity (SOGI). We asked each participant about sexual attraction (answer options, tick all that apply: women/ men/ transwomen/ transmen/ gender non-conforming people/ intersex people/ I do not feel sexual attraction/ other, please specify), sexual partners over their lifetime (answer options, tick all that apply: women/ men/ transwomen/ transmen/ gender non-conforming people/ intersex people/ I have not had sexual experiences/ other, please specify) and sexual identity (answer options: lesbian/ bisexual/ gay/ heterosexual/ asexual/ other, please specify). We further asked about sex assigned at birth and self-identified gender identity [19]: both were taken into account to group participants into gender identity categories. The sexual orientation variable takes into account sexual attraction, sexual behaviour, sexual identity and gender identity: we grouped participants into sexual orientation categories based on the best-fitting answer combination to these questions, giving preference to self-identification [16]. Participants whose answer combinations did not allow us to group them into the categories of lesbian, gay or bisexual [20] were grouped in the sexual orientation category 'non-normative'. This included, for example, participants who identified as gender non-conforming and queer without binary gender, conventional sexual orientation categories such as lesbian, gay or bisexual cannot be determined.

Our questions about socio-economic circumstances included age, religion, education, housing, employment and financial security. Additionally, we asked who knew about participants' SOGI, which we recorded in binary variables (yes/no) for different groups of people (family members, friends, people in household, people living nearby, work colleagues).

To assess violence, we asked a series of yes/no questions about experiences and perpetrators of physical and sexual violence, both for lifetime and the past year. Additionally, we asked participants if they had been coerced into marriage. For participants who had experienced violence, we asked about three signs of post-traumatic stress disorder (PTSD): (1) flashbacks, nightmares or reliving of the traumatic incident, (2) avoidance behaviour and (3) feelings of jumpiness/ irritability/ restlessness. These were based on the diagnostic criteria for PTSD in the DSM-V [21]. We recoded participants who reported all three signs as 'showing signs of PTSD' in a binary variable.

A separate section of the survey asked about health service use and specific mental health outcomes. We do not report on these findings here but do include a binary variable about use of HIV-related healthcare as a proxy for living with HIV, which we hypothesised could be associated with violence because HIV infection is both a consequence of, and risk factor for, violence [22].

\section{Data analysis}

All data were analysed with Stata15 (StataCorp, College Station).

For sample characteristics, we describe median and interquartile range (IQR) for continuous variables and percentages for categorical variables. For categorical outcome variables we describe proportions with $95 \%$ confidence intervals. We assessed bivariate and multivariate associations between experience of violence as the main outcome of interest and other variables. The outcome variable was defined in two ways: 1) lifetime experience of any form of violence (physical and/or sexual) and 2) past year experience of any form of violence (physical and/or sexual).

For analysis of bivariate associations with 'experience of violence', we considered the following variables based on a review of the literature (see, for example, [23-26]) and discussions with our community partner organisations: gender minority status (transgender women, transgender women or gender non-conforming participants), HIV status, rural location, coercion into marriage, financial and housing stability (living in formal versus informal housing), public knowledge of SOGI (among people living in the same household, and people living nearby). Variables that were significantly associated $(p<0.05)$ with the experience of violence outcome variables in bivariate analysis were included in the multivariate logistic regression models.

In the logistic regression models, associations with experience of violence were considered to be statistically significant if $p<0.05$. We present odds ratios, $p$-values and we used $95 \%$ confidence intervals.

For missing data in descriptive statistics and bivariate analysis we describe levels of missingness. In the multivariate logistic regression models we used multiple imputation (MI) to minimise bias [27]. In our MI model, we assumed data to be missing at random, used chained equations and imputed categorical variables with predictive mean matching and binary variables with logistic regression. In the 290 surveys that were excluded due to incompleteness, participants had not provided information beyond initial participant characteristics. Therefore, these surveys were not included in the MI models. 


\section{Regulatory compliance}

The overall study was approved by the Human Research Ethics Committee of the University of Cape Town's Faculty of Health Sciences (HREC 012/2016). Based on this approval, we gained approval from national ethics or health regulatory bodies. Table 1 lists the regulatory approvals in the specific study countries. We followed guidelines and established best practices for research on sexual and gender minorities' health in rights-constrained environments $[15,28]$ : in some countries, obtaining regulatory approval would have significantly increased safety risks for our community partner organisations or research participants. Here, we initiated a community review process instead, where a review board of community members evaluated the risks and benefits of the study. The composition and review process of each community review board, as well as the evaluation of the study proposal, was overseen and approved by the Human Research Ethics Committee at the University of Cape Town's Faculty of Health Sciences. Prior to enrolment, all participants provided informed consent. We ensured complete participant anonymity throughout the data collection process.

\section{Results}

\section{Characteristics of sample}

The 3798 participants were diverse in their sexual orientations, and about one quarter $(n=887)$ of participants identified as a gender minority (transgender woman, transgender man or gender non-conforming; Table 2). The median age was 26 years. Only $42 \%$ of participants reported sufficient financial capacity to meet their everyday needs. Twenty per cent of participants were living with HIV, and $18 \%$ had been coerced into marriage.

\section{Experience of violence}

Table 3 presents the proportion of participants who experienced physical and/or sexual violence, in their lifetime and the past year, and stratifies findings by sexual orientation, gender identity, age, HIV status and forced marriage. Overall, 56\% of participants had experienced some form of violence in their lifetime. In the past year, $29 \%$ of participants had experienced some form of violence; $25 \%$ had experienced physical violence, and $19 \%$ sexual violence.

Experiences of violence were high across participants of all sexual orientations and gender identities. Transgender women had experienced the highest levels of violence: three in four transgender women $(73 \%)$ had experienced any form of violence in their lifetime, and almost half (45\%) in the past year. Compared to cisgender (sexual minority) participants, gender minority participants had experienced significantly higher levels of any form of violence in their lifetime $(p<0.01$ for both; data not shown). Younger sexual and gender minority people experienced higher levels of recent violence, with $30 \%$ of 18-24 year olds having experienced some form of violence in the past year, compared to $25 \%$ of $35-44$ year olds and $9 \%$ of participants over the age of 45 .

Both lifetime and past year experiences of some form of violence were significantly higher among participants who were living with HIV, compared to participants not living with HIV $(p<0.01)$; and among participants who reported being coerced into marriage, compared to participants not coerced into marriage ( $p<0.01$; see also Table 3$)$.

Of participants who had experienced violence in their lifetime, $70 \%$ (95\% CI, 68.2-72.2) believed that it had been motivated by their sexual orientation and/or gender identity (SOGI), 44\% (95\% CI, 41.4-45.9) reported three signs of PTSD, and 25\% (95\% CI, 23.2-27.0) were living with HIV. Of participants who had experienced violence in the past year, $76 \%$ (95\% CI, 74.8-80.1) believed it was SOGI-motivated, 46\% (95\% CI, 43.2-49.6) reported three signs of PTSD and 29\% (95\% CI, 26.432.0) were living with HIV (data not shown).

\section{Factors associated with experience of violence}

In bivariate analysis, variables significantly associated with lifetime experiences of violence were: coercion into

Table 1 Ethical and regulatory approval

\begin{tabular}{ll}
\hline Country & Approval authority and reference number \\
\hline Botswana & Ethics Unit, Office of Research and Development, University of Botswana (UBR/RES/IRB/BIO/009) \\
& Health Research and Development Division, Ministry of Health and Wellness, Republic of Botswana (HPDME: 13/18/1) \\
eSwatini & Scientific and Ethics Committee, Ministry of Health and Social Welfare, Kingdom of Swaziland (no ref. number) \\
Ethiopia & Community review board \\
Kenya & Kenya Medical Research Institute (KEMRI/RES/7/3/1) \\
Lesotho & Research and Ethics Committee, Ministry of Health, Lesotho (ID94-2017) \\
Malawi & University of Malawi, College of Medicine Research and Ethics Committee (P.01/18/2330) \\
South Africa & University of Cape Town Faculty of Health Sciences Human Ethics Research Committee (HREC 012/2016) \\
Zambia & Community review board \\
Zimbabwe & Medical Research Council of Zimbabwe (MRCZ/A/2303) \\
\hline
\end{tabular}


Table 2 Characteristics of sample

\begin{tabular}{|c|c|c|}
\hline \multicolumn{3}{|l|}{ Sample characteristics $(N=3798)$} \\
\hline \multicolumn{3}{|l|}{ Age } \\
\hline Median (IQR) & 26 & $18-59$ \\
\hline Range & & $18-64$ \\
\hline Missing (n, \%) & 180 & 4.74 \\
\hline Country & $\mathbf{n}$ & $\%$ \\
\hline Botswana & 618 & 16.27 \\
\hline eSwatini & 104 & 2.74 \\
\hline Ethiopia & 198 & 5.21 \\
\hline Kenya & 976 & 25.70 \\
\hline Lesotho & 173 & 4.56 \\
\hline Malawi & 197 & 5.19 \\
\hline South Africa & 832 & 21.91 \\
\hline Zambia & 353 & 9.29 \\
\hline Zimbabwe & 347 & 9.14 \\
\hline Sexual orientation & $\mathbf{n}$ & $\%$ \\
\hline Lesbian & 907 & 23.88 \\
\hline Bisexual & 734 & 19.33 \\
\hline Bisexual women & 202 & 5.32 \\
\hline Bisexual men & 487 & 12.82 \\
\hline Gay & 1686 & 44.39 \\
\hline Non-normative & 270 & 7.11 \\
\hline Heterosexual ${ }^{a}$ & 185 & 4.87 \\
\hline Missing & 16 & 0.42 \\
\hline Gender identity & $\mathbf{n}$ & $\%$ \\
\hline Cisgender woman ${ }^{a}$ & 911 & 23.99 \\
\hline Cisgender man ${ }^{a}$ & 1911 & 50.32 \\
\hline Transgender woman & 383 & 10.08 \\
\hline Transgender man & 284 & 7.48 \\
\hline Gender non-conforming & 188 & 4.95 \\
\hline Non-normative & 32 & 0.84 \\
\hline Missing & 89 & 2.34 \\
\hline Characteristics & $\mathbf{n}$ & $\%$ \\
\hline Not enough money for basic needs $(N=3710)^{b}$ & 2131 & 56.11 \\
\hline Living in informal housing or on the street $(N=3780)$ & 235 & 6.19 \\
\hline Living in rural area $(N=3763)$ & 333 & 8.77 \\
\hline Accessing HIV care and treatment $(N=3651)$ & 771 & 20.30 \\
\hline Coerced into marriage $(N=3570)$ & 673 & 17.72 \\
\hline Living with people who know their SOGl & 1256 & 33.07 \\
\hline Living near people who know their SOGl & 899 & 23.67 \\
\hline $\begin{array}{l}\text { IQR Interquartile Range, SOGI sexual orientation and/or gender } \\
\text { aBecause the inclusion criteria were being a sexual minority an } \\
\text { minority, participants who identified as heterosexual are gende } \\
\text { (transgender women or men, or gender non-conforming peop } \\
\text { participants who identified as cisgender are sexual minorities ( } \\
\text { lesbian, bisexual or gay) } \\
\text { b } \mathrm{N} \text { varies due to missing data }\end{array}$ & $\begin{array}{l}\text { identity } \\
\text { d/or a } 9\end{array}$ & $\begin{array}{l}\text { ender } \\
\text { ties } \\
\text { as }\end{array}$ \\
\hline
\end{tabular}

marriage, having people living nearby and people living in the same household know one's SOGI, being a gender minority, HIV status, and living in informal housing (Table 4). The same variables were also significantly associated with experience of violence in the past year.

Table 5 presents the variables that showed independent significant associations with lifetime and past year experience of violence in multivariate logistic regression analysis; these were similar for both outcomes. The variable most strongly associated with having experienced lifetime and past year violence was being coerced into marriage (lifetime adjusted odds ratio (AOR) 3.02; past year AOR 2.72). Other factors significantly and positively associated with these outcomes were people living nearby knowing about one's sexual orientation and/or gender identity (lifetime AOR 1.90; past year AOR 1.42), and living with HIV (lifetime AOR 1.47; past year 1.63).

Compared to cisgender (sexual minority) men, the likelihood of experiencing lifetime violence was higher for transgender women (AOR, 2.51; 95\% CI, 1.88-3.36, $p<0.01$ ), for gender non-conforming people (AOR, 2.42; 95\% CI, 1.64-3.58, $p<0.01$ ) and for cisgender (sexual minority) women (AOR, 1.94; 95\% CI, 1.48-2.55, $p<$ 0.01).

\section{Discussion}

Our exploratory study provides the first large-scale data on sexual orientation, gender identity and violence from the African continent. It shows that sexual and gender minorities in Southern and Eastern Africa face high levels of violence, and that often, sexual and gender minorities perceive this violence to be motivated by their sexual orientation and/or gender identity. Whilst more than half of all sexual and gender minorities in our study had experienced violence, bisexual women, transgender women and gender non-conforming people seem to be most at risk.

Our study is subject to some important limitations. First, it is an exploratory study, and our study design was not robust enough to investigate causality or protective factors. As such, it cannot identify predictors or risk factors for violence, and only reports factors that are associated with violence. Second, there are no standardised ways of asking about SOGI [16], or violence, and this limits the comparability of our findings. Third, others have found that community venue-based sampling might overestimate health concerns [29]. We have tried to mitigate this by broadening our sample through sampling online [17]. It is important to note that the levels of experiences of violence did not significantly differ between community venue-based and online sample. Where we did see a significant difference, it seemed due to the difference between fieldworker and self-administered surveys, which is in line with 
Table 3 Experience of violence in lifetime and past year among sexual and gender minority sample

\begin{tabular}{|c|c|c|c|}
\hline & Any form of violence & Physical violence & Sexual violence \\
\hline Overall sample & $\%(95 \% \mathrm{Cl})$ & $\%(95 \% \mathrm{Cl})$ & $\%(95 \% \mathrm{Cl})$ \\
\hline Lifetime & $56.0(54.4-57.7)$ & $47.3(45.7-49.0)$ & $38.9(37.3-40.5)$ \\
\hline Past year & $29.2(27.8-30.7)$ & $25.2(23.8-26.6)$ & $19.2(17.9-20.5)$ \\
\hline \multicolumn{4}{|l|}{ By country (lifetime) } \\
\hline Botswana & $38.7(34.8-42.6)$ & $31.1(27.5-34.9)$ & $26.5(23.1-30.1)$ \\
\hline Eswatini & $72.8(63.4-80.6)$ & $58.3(48.5-67.4)$ & $49.5(39.9-59.1)$ \\
\hline Ethiopia & $43.8(36.2-51.6)$ & $36.9(29.7-44.6)$ & $30.0(23.4-37.6)$ \\
\hline Lesotho & $48.5(41.0-56.1)$ & $46.4(38.9-54.0)$ & $22.6(16.9-29.6)$ \\
\hline Kenya & $61.3(58.2-64.4)$ & $53.0(49.9-56.2)$ & $43.9(40.8-47.1)$ \\
\hline Malawi & $53.1(46.0-60.0)$ & $41.3(34.6-48.4)$ & $41.5(34.8-49.0)$ \\
\hline South Africa & $65.3(61.9-68.7)$ & $55.0(51.4-58.5)$ & $47.9(44.4-51.5)$ \\
\hline Zambia & $60.6(55.1-65.8)$ & $53.3(47.8-58.8)$ & $34.4(29.4-40.0)$ \\
\hline Zimbabwe & $53.2(47.8-58.6)$ & $42.9(37.7-48.4)$ & $38.6(33.5-44.0)$ \\
\hline By sexual orientation & $\%(95 \% \mathrm{Cl})$ & $\%(95 \% \mathrm{Cl})$ & $\%(95 \% \mathrm{Cl})$ \\
\hline \multicolumn{4}{|l|}{ Lesbian } \\
\hline Lifetime & $56.8(53.5-60.1)$ & $47.6(44.2-51.0)$ & $39.7(36.5-43.1)$ \\
\hline Past year & $28.1(25.2-31.3)$ & $24.4(21.6-27.4)$ & $16.1(13.8-18.8)$ \\
\hline \multicolumn{4}{|l|}{ Bisexual (women) } \\
\hline Lifetime & $62.0(55.1-68.5)$ & $54.5(47.5-61.3)$ & $47.5(40.6-54.5)$ \\
\hline Past year & $32.7(26.5-39.5)$ & $27.0(21.3-33.6)$ & $20.1(15.1-26.3)$ \\
\hline \multicolumn{4}{|l|}{ Bisexual (men) } \\
\hline Lifetime & $47.2(42.7-51.8)$ & $40.1(35.7-44.6)$ & $31.5(27.4-35.8)$ \\
\hline Past year & $25.4(21.7-29.6)$ & $22.2(18.6-26.2)$ & $17.5(14.3-21.3)$ \\
\hline \multicolumn{4}{|l|}{ Gay } \\
\hline Lifetime & $54.9(52.5-57.4)$ & $46.1(43.7-48.6)$ & $36.4(34.1-38.8)$ \\
\hline Past year & $30.3(24.7-31.4)$ & $26.2(24.1-28.4)$ & $20.5(18.6-22.5)$ \\
\hline \multicolumn{4}{|l|}{ Non-normative } \\
\hline Lifetime & $68.1(62.1-73.5)$ & $58.8(52.6-64.6)$ & $54.1(48.0-60.1)$ \\
\hline Past year & $28.4(23.1-34.2)$ & $23.5(18.7-29.1)$ & $20.8(16.2-26.2)$ \\
\hline By gender identity & $\%(95 \% \mathrm{Cl})$ & $\%(95 \% \mathrm{Cl})$ & $\%(95 \% \mathrm{Cl})$ \\
\hline \multicolumn{4}{|l|}{ Transgender women } \\
\hline Lifetime & $73.0(68.2-77.3)$ & $62.5(57.4-67.3)$ & $54.4(49.2-59.4)$ \\
\hline Past year & $44.6(39.5-49.8)$ & $39.9(35.0-45.0)$ & $30.1(25.6-35.0)$ \\
\hline \multicolumn{4}{|l|}{ Transgender men } \\
\hline Lifetime & $54.4(48.5-60.3)$ & $46.3(40.4-52.3)$ & $40.6(34.9-46.6)$ \\
\hline Past year & $32.8(27.5-38.7)$ & $29.1(24.0-34.8)$ & $24.2(19.4-29.7)$ \\
\hline \multicolumn{4}{|l|}{ Gender non-conforming } \\
\hline Lifetime & $69.8(62.5-76.2)$ & $59.9(52.4-67.0)$ & $56.4(48.9-63.6)$ \\
\hline Past year & $36.8(29.9-44.3)$ & $31.2(24.7-38.5)$ & $24.6(18.7-31.6)$ \\
\hline By age group & $\%(95 \% \mathrm{Cl})$ & $\%(95 \% \mathrm{Cl})$ & $\%(95 \% \mathrm{Cl})$ \\
\hline \multicolumn{4}{|l|}{$18-24$ years } \\
\hline Lifetime & $51.3(48.7-54.0)$ & $41.7(39.1-44.3)$ & $36.2(33.7-38.7)$ \\
\hline Past year & $30.2(27.9-32.7)$ & $25.7(23.5-28.1)$ & $18.9(16.9-21.0)$ \\
\hline \multicolumn{4}{|l|}{$25-34$ years } \\
\hline Lifetime & $58.7(56.3-61.1)$ & $51.3(48.9-53.7)$ & $40.4(38.1-42.8)$ \\
\hline Past year & $29.5(27.3-31.7)$ & $25.7(23.7-27.9)$ & $20.0(18.2-22.0)$ \\
\hline
\end{tabular}


Table 3 Experience of violence in lifetime and past year among sexual and gender minority sample (Continued)

\begin{tabular}{|c|c|c|c|}
\hline & Any form of violence & Physical violence & Sexual violence \\
\hline \multicolumn{4}{|l|}{$35-44$ years } \\
\hline Lifetime & $61.7(56.3-66.8)$ & $51.7(46.3-57.0)$ & $42.9(37.6-48.3)$ \\
\hline Past year & $25.5(21.0-30.5)$ & $21.2(17.1-26.0)$ & $16.0(12.4-20.4)$ \\
\hline \multicolumn{4}{|l|}{$45-54$ years } \\
\hline Lifetime & $60.5(45.2-74.0)$ & $51.2(36.4-65.7)$ & $37.2(24.1-52.6)$ \\
\hline Past year & $9.3(3.5-22.5)$ & $9.3(3.5-22.5)$ & $2.3(3.1-15.1)$ \\
\hline \multicolumn{4}{|l|}{$>55$ years } \\
\hline Lifetime & $62.5(26.5-88.5)$ & $62.5(26.5-88.5)$ & $25.0(5.7-64.9)$ \\
\hline Past year & 0 (no observations) & 0 (no observations) & 0 (no observations) \\
\hline \multicolumn{4}{|c|}{ By HIV status } \\
\hline \multicolumn{4}{|c|}{ Living with HIV } \\
\hline Lifetime & $65.9(62.3-69.2)$ & $57.0(53.4-60.5)$ & $46.8(43.2-50.4)$ \\
\hline Past year & $40.2(36.7-43.8)$ & $35.4(32.0-39.0)$ & $26.8(23.7-30.2)$ \\
\hline \multicolumn{4}{|c|}{ Not living with HIV } \\
\hline Lifetime & $53.1(51.2-55.0)$ & $44.6(42.7-46.5)$ & $36.5(34.7-38.3)$ \\
\hline Past year & $26.2(24.6-27.9)$ & $22.3(20.8-23.9)$ & $17.1(15.7-18.5)$ \\
\hline \multicolumn{4}{|c|}{ By coerced marriage } \\
\hline \multicolumn{4}{|c|}{ Forced to marry } \\
\hline Lifetime & $75.6(72.2-78.7)$ & $67.3(63.6-70.7)$ & $56.2(52.4-59.9)$ \\
\hline Past year & $46.8(43.1-50.7)$ & $41.5(37.8-45.3)$ & $33.8(30.3-37.5)$ \\
\hline \multicolumn{4}{|c|}{ Not forced to marry } \\
\hline Lifetime & $51.4(49.5-53.2)$ & $42.6(40.8-44.4)$ & $34.6(32.9-36.4)$ \\
\hline Past year & $24.8(23.2-26.4)$ & $21.2(19.7-22.7)$ & $15.4(14.1-16.7)$ \\
\hline
\end{tabular}

Table 4 Bivariate associations with lifetime and past year violence

\begin{tabular}{|c|c|c|c|c|}
\hline \multirow[b]{2}{*}{ Variable $^{\mathrm{a}}$} & \multicolumn{2}{|c|}{ Lifetime experience of violence* } & \multicolumn{2}{|c|}{ Past year experience of violence* } \\
\hline & $\begin{array}{l}\text { OR } \\
(95 \% \mathrm{Cl})\end{array}$ & $p$-value & $\begin{array}{l}\text { OR } \\
(95 \% \mathrm{Cl})\end{array}$ & $p$-value \\
\hline Coerced into marriage & $\begin{array}{l}2.93 \\
(2.42-3.55)\end{array}$ & $<0.01$ & $\begin{array}{l}2.68 \\
(2.25-3.18)\end{array}$ & $<0.01$ \\
\hline People living nearby know SOGI & $\begin{array}{l}2.17 \\
(1.84-2.55)\end{array}$ & $<0.01$ & $\begin{array}{l}1.39 \\
(1.18-1.64)\end{array}$ & $<0.01$ \\
\hline People living within same household know SOGl & $\begin{array}{l}1.77 \\
(1.54-2.05)\end{array}$ & $<0.01$ & $\begin{array}{l}1.24 \\
(1.06-1.44)\end{array}$ & $<0.01$ \\
\hline Being a gender minority & $\begin{array}{l}1.72 \\
(1.47-2.02)\end{array}$ & $<0.01$ & $\begin{array}{l}1.76 \\
(1.49-2.07)\end{array}$ & $<0.01$ \\
\hline Living with HIV & $\begin{array}{l}1.70 \\
(1.44-2.02)\end{array}$ & $<0.01$ & $\begin{array}{l}1.89 \\
(1.59-2.24)\end{array}$ & $<0.01$ \\
\hline Living in informal housing & $\begin{array}{l}0.59 \\
(0.44-0.78)\end{array}$ & $<0.01$ & $\begin{array}{l}0.52 \\
(0.40-0.69)\end{array}$ & $<0.01$ \\
\hline Survey taken online & $\begin{array}{l}1.12 \\
(0.96-1.32)\end{array}$ & 0.16 & $\begin{array}{l}0.62 \\
(0.51-0.74)\end{array}$ & $<0.01$ \\
\hline
\end{tabular}

OR Odd's Ratio, $\mathrm{Cl}$ Confidence Interval, SOGI sexual orientation and/or gender identity

*only reporting associations significant at $p<0.05$

${ }^{a} \mathrm{~N}$ varies due to missing data; variable $\mathrm{N}$ for lifetime experience of violence: Coerced into marriage $(N=3555)$, People living nearby know SOGI (3590), People living within same household know SOGI $(N=3590)$, Being a gender minority $(N=3517)$, Living with HIV $(N=3464)$, Living in informal housing $(N=3585)$; variable $\mathrm{N}$ for past year experience of violence: Coerced into marriage $(N=3538)$, Living with HIV $(N=3450)$, Being a gender minority $(N=3498)$, People living nearby know SOGI $(N=3571)$, People living within same household know SOGI $(N=3571)$, Survey taken online $(N=3583)$, Living in informal housing $(N=3567)$ 
Table 5 Multivariate analysis for factors associated with lifetime and past year experience of violence

\begin{tabular}{|c|c|c|c|c|}
\hline \multirow[b]{2}{*}{ Variable } & \multicolumn{2}{|c|}{ Lifetime experience of violence* } & \multicolumn{2}{|c|}{ Past year experience of violence* } \\
\hline & $\begin{array}{l}\text { OR } \\
(95 \% \mathrm{Cl})\end{array}$ & $p$-value & $\begin{array}{l}\text { OR } \\
(95 \% \mathrm{Cl})\end{array}$ & $p$-value \\
\hline Coerced into marriage & $\begin{array}{l}3.02 \\
(2.48-3.69)\end{array}$ & $<0.01$ & $\begin{array}{l}2.72 \\
(2.27-3.27)\end{array}$ & $<0.01$ \\
\hline \multicolumn{5}{|c|}{ Gender identity (reference category cisgender man) } \\
\hline Transgender woman & $\begin{array}{l}2.51 \\
(1.88-3.36)\end{array}$ & $<0.01$ & $\begin{array}{l}2.19 \\
(1.67-2.88)\end{array}$ & $<0.01$ \\
\hline Gender non-conforming & $\begin{array}{l}2.42 \\
(1.64-3.58)\end{array}$ & $<0.01$ & $\begin{array}{l}1.87 \\
(1.29-2.71)\end{array}$ & $<0.01$ \\
\hline Cisgender woman & $\begin{array}{l}1.94 \\
(1.48-2.55)\end{array}$ & $<0.01$ & $\begin{array}{l}1.59 \\
(1.14-2.23)\end{array}$ & $<0.01$ \\
\hline People living nearby know SOGl & $\begin{array}{l}1.90 \\
(1.56-2.31)\end{array}$ & $<0.01$ & $\begin{array}{l}1.42 \\
(1.16-1.74)\end{array}$ & $<0.01$ \\
\hline Living with HIV & $\begin{array}{l}1.47 \\
(1.23-1.77)\end{array}$ & $<0.01$ & $\begin{array}{l}1.63 \\
(1.35-1.97)\end{array}$ & $<0.01$ \\
\hline Not enough money for everyday needs & $\begin{array}{l}0.82 \\
(0.71-0.95)\end{array}$ & $<0.01$ & $\begin{array}{l}0.63 \\
(0.53-0.75)\end{array}$ & $<0.01$ \\
\hline
\end{tabular}

$A O R$ adjusted odd's ratio, $\mathrm{Cl}$ confidence interval, SOGI sexual orientation and/or gender identity

* only reporting associations significant at $p<0.05$

observations in other studies [30], which also found higher levels of reported violence in self-administered surveys. Lastly, we found some associations that were opposite to what we expected (for example, informal housing was negatively associated with violence). These are likely confounded due to other unmeasured variables.

Despite these limitations, our findings are congruent with and confirm grey literature findings of high levels of violence experienced by sexual and gender minorities in the study countries (see, for example, $[23-26,31]$ ), as well as findings of high levels of violence experienced by sexual and gender minority people worldwide [2-4]. Our findings highlight that especially younger sexual and gender minority people are experiencing high levels of violence.

Compared to the levels of violence experienced by the general population in each country (assumed to be cisgender and heterosexual), sexual and gender minority people in our study reported higher levels of violence. For example, in Botswana, studies suggest that $10-11 \%$ of women in the general population have experience sexual violence in their life $[32,33]$, compared to $27 \%$ of sexual and gender minority people in our study. The Kenyan Demographic and Health Survey (DHS) from 2014 estimates that $39 \%$ of women in the general population have experienced physical violence in their lifetime [34], compared to our findings of $53 \%$ of Kenyan sexual and gender minority people. The 2015 Zimbabwe DHS found that one in seven women in the general population (14\%) had experienced sexual violence in their lifetime [35]. Among Zimbabwean sexual and gender minority people in our study, 39\% had experienced sexual violence. While the comparability of these studies might be limited, the much higher levels of violence reported by sexual and gender minorities in our study seem to indicate reasons beyond methodological differences. This suggestion is confirmed by literature from other contexts, which has consistently found higher levels among sexual and gender minorities compared to the general population $[2,3]$.

Yet, at the same time, sexual and gender minorities are usually not catered for in violence prevention and survivor support services [36]. Worse, the laws that criminalise same-sex sexuality in six of the nine countries of our study often actively discourage sexual and gender minority survivors of violence to report experiences of violence to the police or to seek healthcare for fear of arrest, intimidation or blackmail [31,37]. Besides the laws, harmful social attitudes and norms born out of patriarchal heterosexism do not only harm sexual and gender minority people directly (ie. through violence), but also indirectly by impeding access to healthcare and justice. Studies from Southern Africa have shown that sexual orientation and gender identity-related prejudice leads to discrimination of sexual and gender minorities in healthcare and the criminal justice system, including when seeking care after experiencing violence [36, 38-40].

Our study found that having been coerced into (heterosexual) marriage held the strongest association with experiencing violence. We are not aware of other work that has looked at the relationship between coerced marriage and violence among sexual and gender minorities. We think that there might be a few explanations for this. One, sexual and gender minorities who are coerced into marriage could be more likely to live in communities 
that hold conservative, heteropatriarchal normative ideas about religion, gender roles, family and social structures - which could be the reason they are coerced into marriage in the first place. It is likely that homo- and transphobic attitudes are more prevalent in these communities, which would also increase the risk for experiencing SOGI-related violence. Conservative, heterosexist contexts are well documented in most of the countries of our research [41, 42], and other researchers have shown how violence has been used to police (and discourage) non-conforming sexual orientations and gender identities [23, 43]. Two, it is possible that sexual and gender minority people in coerced heterosexual marriages are at higher risk for violence by their spouse if their sexual orientation or gender identity is revealed, and being forced to have sex in coerced heterosexual marriages is a form of sexual violence itself. Three, it is also possible that sexual and gender minority people who have been the targets of violence feel that heterosexual marriage might offer them protection from SOGI-motivated violence, and consider this reason for marriage a form of coercion. Lastly, heterosexual marriage might provide economic and financial stability, which is especially important for sexual and gender minority people who are economically precarious, which is also confirmed by our findings. We recommend conducting qualitative research to better understand our quantitative findings.

\section{Conclusion}

Our study provides important evidence on the high levels of violence experienced by sexual and gender minority people in Eastern and Southern Africa. Our findings highlight the importance of the African Commission's Resolution 275 [10] and emphasise the need for states to protect sexual and gender minority people from violence, following the practical steps outlined in the Ekurhuleni Declaration [44]. States need to be willing to enforce their existing protective legal provisions (for example, the right to non-discrimination) equally to protect sexual and gender minorities. Further, states should repeal provisions that criminalise same-sex sexuality and/or non-conforming gender expression in order to reduce the vulnerability of sexual and gender minority people and increase their access to healthcare, justice and social support systems. Beyond legal reform, heteropatriarchal and heterosexist social and cultural norms that place sexual and gender minority people at risk for violence, including those that exist among healthcare providers, need to be challenged through on-going education by states and civil society organisations. An awareness of the severe and complex vulnerabilities to violence that sexual and gender minority people face is essential for efforts to reduce such violence.
Abbreviations

PTSD: Post-traumatic stress disorder; SOGI: Sexual orientation and gender identity

\section{Acknowledgments}

Our study would not have been possible without the dedication and hard work of all community partner organisations from the Southern and Eastern African Research Collective for Health (SEARCH), nor without the funding and support from COC Netherlands. We are grateful to everyone who participated and answered the survey, especially in contexts where identifying as a sexual and/or gender minority is a risk. Thank you to Dr. Anneli Hardy for statistical advice and guidance. Lastly, we would like to thank Mina Haji, Lilian Mubangizi and Marie Lunau for their research assistance on this study, and Thoko Malaba and Talia Meer for comments on earlier versions of this manuscript.

The Southern and Eastern African Research Collective for Health (SEARCH) comprises of the following 24 organisations: BONELA, Lesbians, Gays and Bisexuals of Botswana, Rainbow Identity Association (Botswana); two organisations in Ethiopia (names withheld for security reasons); The People's Matrix Organisation (Lesotho); Ishtar-MSM, Jintsiangu, Maaygo, Minority Women in Action, National Gay and Lesbian Human Rights Commission, People Marginalized and Aggrieved (Kenya); Centre for the Development of People (Malawi); COC Nederland (Netherlands); Durban Lesbian and Gay Centre, Gender Health and Justice Research Unit (University of Cape Town), OUT LGBT Wellbeing, Triangle Project (South Africa); Rock of Hope (Swaziland); Friends of Rainka, The Lotus Identity, Transbantu Zambia (Zambia); GALZ - An LGBTI Association in Zimbabwe, Sexual Rights Centre (Zimbabwe).

\section{Authors' contributions}

All authors co-conceptualised the study. MK, AMC, VO and MZ collected data. $\mathrm{AM} 1, \mathrm{KD}, \mathrm{CM}, \mathrm{NM}$ and $\mathrm{AM} 2$ oversaw data collection. AM1, KD and CM performed data analysis. AM1 drafted the manuscript. All authors provided feedback and edits. All authors read and approved the final manuscript.

\section{Funding}

Funding for the research project was provided by COC Netherlands. The funder did not play any role in the design of the study, in collection, analysis, and interpretation of data, nor in writing the manuscript. Open Access funding enabled and organized by Projekt DEAL.

\section{Availability of data and materials}

The datasets generated during the current study are not publicly available in order to minimise the risk of deliberate misinterpretation or misuse to further state-sponsored homo- and transphobia. The dataset includes data on mental ill-health. Given the long history of pathologisation of nonconforming sexual orientations and gender identities, the authors fear that data that negatively represents the negative mental health consequences of homo- and transphobia might be purposefully misinterpreted to further homo- and transphobic arguments. Data are available from the corresponding author upon reasonable request and with permission of the other partners of the Southern and East African Research Collective for Health.

\section{Ethics approval and consent to participate}

The study was approved by the Human Research Ethics Committee of the University of Cape Town's Faculty of Health Sciences (HREC 012/2016) as well as by the following national regulatory bodies: Ethics Unit, Office of Research and Development, University of Botswana (UBR/RES/RB/BIO/009); Health Research and Development Division, Ministry of Health and Wellness, Republic of Botswana (HPDME: 13/18/1); Scientific and Ethics Committee, Ministry of Health and Social Welfare, Kingdom of Swaziland (no ref. number); Kenya Medical Research Institute (KEMRI/RES/7/3/1); Research and Ethics Committee, Ministry of Health, Lesotho (ID94-2017); University of Malawi, College of Medicine Research and Ethics Committee (P.01/18/2330); and the Medical Research Council of Zimbabwe (MRCZ/A/2303). Same-sex sexuality and visible gender non-conformity are criminalised in most of the study countries, and identifying/ being identified as a sexual and/or gender minority can carry significant risks of stigma, discrimination or violence.

Therefore, we had to carefully consider the risks associated with participating in our study, specifically around the potential disclosure of sexual orientation or gender identity to third parties outside the study team. In order to 
maintain full anonymity for participants throughout the data collection process, participants were not asked to sign their name for written informed consent. This ensured that, should any of the questionnaires or other study documentation fall into the hands of state authorities or others, individual participants could not be identified. Instead, all participants provided written informed consent by ticking a box on an informed consent statement. This procedure was approved as part of our study protocol by the ethics and regulatory bodies we have listed.

\section{Consent for publication}

Not applicable.

\section{Competing interests}

The authors declare that they have no competing interests.

\section{Author details}

${ }^{1}$ Gender Health and Justice Research Unit, University of Cape Town, Cape Town, South Africa. ${ }^{2}$ Department of Medical Ethics and History of Medicine, Universitätsmedizin Göttinge, Göttingen, Germany. ${ }^{3}$ The Lotus Identity, Lusaka, Zambia. ${ }^{4}$ Lesbians, Gays and Bisexuals of Botswana, Gaborone, Botswana. ${ }^{5}$ Liverpool School of Tropical Medicine and Botswana UPenn Partnership, Gaborone, Botswana. ${ }^{6}$ Department of Sociology, University of Zimbabwe, Harare, Zimbabwe. ${ }^{7}$ College of Medicine, University of Malawi, Blantyre, Malawi. ${ }^{8}$ Maaygo, Kisumu, Kenya. ${ }^{9}$ Friends of Rainka, Lusaka, Zambia.

Received: 11 June 2020 Accepted: 21 January 2021

\section{Published online: 15 February 2021}

\section{References}

1. Logie C. The case for the World Health Organization's commission on the social determinants of health to address sexual orientation. Am J Public Health. 2012 Jul;102(7):1243-6.

2. Stotzer RL. Violence against transgender people: a review of United States data. Aggress Violent Behav. 2009;14(3):170-9.

3. Rothman EF, Exner D, Baughman AL. The prevalence of sexual assault against people who identify as gay, lesbian, or bisexual in the United States: a systematic review. Trauma Violence Abuse. 2011;12(2):55-66.

4. Blondeel K, de Vasconcelos S, García-Moreno C, Stephenson R, Temmerman $\mathrm{M}$, Toskin I. Violence motivated by perception of sexual orientation and gender identity: a systematic review. Bull World Health Organ. 2018;96(1): 29-41L.

5. Pega F, Veale JF. The case for the World Health Organization's commission on social determinants of health to address gender identity. Am J Public Health. 2015;105(3):e58-62.

6. Human rights, sexual orientation and gender identity. HRC/RES/17/19. Geneva: United Nations Human Rights Council; 2011

7. Discriminatory laws and practices and acts of violence against individuals based on their sexual orientation and gender identity. HRC/19/41. Geneva: United Nations Human Rights Council; 2011.

8. Human rights, sexual orientation and gender identity. HRC/RES/27/32 Geneva: United Nations Human Rights Council; 2014.

9. Discrimination and violence against individuals based on their sexual orientation and gender identity. HRC/29/23. Geneva: United Nations Human Rights Council; 2015.

10. African Commission on Human and Peoples' Rights. 275: Resolution on Protection against Violence and other Human Rights Violations against Persons on the basis of their real or imputed Sexual Orientation or Gender Identity. Banjul, Gambia; 2014.

11. Protection against violence and discrimination based on sexual orientation and gender identity. HRC/RES/32/2. Geneva: United Nations Human Rights Council; 2016.

12. Report of the Independent Expert on protection against violence and discrimination based on sexual orientation and gender identity. A/HRC/38/ 43. Geneva: United Nations Human Rights Council; 2018.

13. African Commission on Human and Peoples' Rights. Ending violence and other human rights violations based on sexual orientation and gender identity: A joint dialogue of the African Commission on Human and Peoples' Rights, Inter-American Commission on Human Rights and United Nations. Pretoria; 2016.

14. Carroll A, Mendos LR. State-sponsored homophobia - a world survey of sexual orientation laws: criminalisation, protection and recognition. Geneva:
ILGA World; 2017. Available from: http://ilga.org/downloads/02_LGA_State_ Sponsored_Homophobia_2016_ENG_WEB_150516.pdf

15. amfAR, International AIDS Vaccine Initiative, Johns Hopkins University Center for Public Health and Human Rights, United Nationals Development Programme. Respect Protect Fulfill: Best practices guidance in conducting HIV research with gay, bisexual, and other men who have sex with men (MSM) in rights- constrained environments. Best practices guidance in conducting HIV research with gay, bisexual and other men who have sex with men (MSM) in rights-constrained environments. amfAR; 2015.

16. Meyer $\mathbb{H}$, Wilson PA. Sampling lesbian, gay, and bisexual populations. J Couns Psychol. 2009;56(1):23-31.

17. Rosser BRS, Oakes JM, Bockting WO, Miner M. Capturing the social demographics of hidden sexual minorities: an internet study of the transgender population in the United States. Sex Res Soc Policy. 2007;4(2): 50-64.

18. Müller A, Daskilewicz K, Southern and East African Research Collective on Health. Are we doing alright? Realities of violence, mental health, and access to healthcare related to sexual orientation and gender identity and expression in Botswana: Research report based on a community-led study in nine countries. Amsterdam: COC Netherlands; 2019. Available from: http://www.ghjru.uct.ac.za/ghiru/publications/recent-research-reports

19. James SE, Herman JL, Rankin S, Keisling M, Mottet L, Anafi M. The Report of the 2015 U.S. Transgender Survey. Washington, DC; 2016.

20. Better A, Simula B. How and for whom does gender matter ? Rethinking the concept of sexual orientation. Sexualities. 2015;18(5/6):665-80.

21. American Psychiatric Association. Diagnostic and statistical manual of mental disorders. 5th ed. Arlington: American Psychiatric Association; 2013.

22. Artz L, Klazinga L, Müller A. Sexual and gender-based violence and HIV in South Africa: an HIV- facility based study. South African Med J. 2020;10(5): 377-81.

23. Nath D. 'We'll show you you're a woman' - violence and discrimination against black lesbians and transgender men in South Africa. New York: Human Rights Watch; 2011.

24. Sandfort TGM, Baumann LRM, Matebeni Z, Reddy V, Southey-Swartz I. Forced sexual experiences as risk factor for self-reported HIV infection among southern African lesbian and bisexual women. PLoS One. 2013;8(1): e53552.

25. Matebeni Z, Reddy V, Sandfort T, Southey-Swartz I. 'I thought we are safe': Southern African lesbians' experiences of living with HIV. Cult Health Sex. 2013;15(Suppl (May)):34-47.

26. Gateru N. The lived experiences of lesbian, bisexual and queer women. GALCK: Nairobi; 2016.

27. Van Ginkel JR, Sijtsma K, Van Der Ark LA, Vermunt JK. Incidence of missing item scores in personality measurement, and simple item-score imputation. Methodology. 2010;6(1):17-30.

28. Amon JJ, Baral SD, Beyrer C, Kass NE. Human rights research and ethics review: protecting individuals or protecting the state? PLOS. 2012;9(10): e1001325.

29. Hendricks ML, Testa RJ. A conceptual framework for clinical work with transgender and gender nonconforming clients: an adaptation of the minority stress model. Prof Psychol Res Pract. 2012;43(5):460-7.

30. Ward CL, Artz L, Leoschut L, Kassanjee R, Burton P. Sexual violence against children in South Africa: a nationally representative cross-sectional study of prevalence and correlates. Lancet Glob Health. 2018;6(4):e460-8.

31. United Nationals Development Programme, Southern African Litigation Centre, Lesbians Gays and Bisexuals of Botswana. "The law needs to change, we want to be free" - the impact of laws criminalising samesex relationships in Botswana. Johannesburg: Southern Africa Litigation Centre; 2018.

32. Tsai AC, Leiter K, Heisler M, lacopino V, Wolfe W, Shannon K, et al. Prevalence and correlates of forced sex perpetration and victimization in Botswana and Swaziland. Am J Public Health. 2011;101(6):1068-74.

33. Machisa M, Jewkes R, Morna CL, Rama K. The war at home: gender based violence indicators project: Gauteng research report. Johannesburg: Gender Links; 2011.

34. Kenya National Bureau of Statistics. Kenya Demographic and Health Survey 2014. Nairobi; 2014. Available from: https://dhsprogram.com/pubs/pdf/fr3 08/fr308.pdf

35. Zimbabwe National Statistics Agency and ICF International. Zimbabwe demographic and health survey 2015. Harare; 2015. Available from: https:// dhsprogram.com/pubs/pdf/FR322/FR322.pdf 
36. Müller A, Meer T. Access to justice for south African lesbian, gay, bisexual and transgender survivors of sexual assault. Cape Town: Gender Health and Justice Research Unit; 2018.

37. Gay and Lesbian Coalition of Kenya (GALCK), National Gay and Lesbian Human Rights Commission (NGLHRC), Coalition of African Lesbians (CAL) \& SRI (SRI). The United Nations Universal Periodic Review of Kenya -21st session (Jan-Feb 2015). 2015;m:1-6. Available from: http://www. sexualrightsinitiative.com/wp-content/uploads/UPR21_SRI_stakeholdersubmission_Kenya.pdf

38. Meer T, Müller A. "They treat us like we're not there": queer bodies and the social production of healthcare spaces. Health Place. 2017:45:92-8.

39. Müller A, Spencer S, Meer T, Daskilewicz K. The no-go zone: a qualitative study of access to sexual and reproductive health services for sexual and gender minority adolescents in southern Africa. Reprod Health. 2018:15(1):1-15.

40. Müller A. Scrambling for access: availability, accessibility, acceptability and quality of healthcare for lesbian, gay, bisexual and transgender people in South Africa. BMC Int Health Hum Rights. 2017;17(1):16.

41. Muzenda G. Canaries in the coal mines: an analysis of spaces for LGBTIQ activism in Botswana. Johannesburg: The Other Foundation; 2016. Available from: http://theotherfoundation.org/wp-content/uploads/2016/10/Canaries_ Summary_epub_Draft4_MJ6.pdf

42. Logie CH, Perez-Brumer A, Woolley E, Madau V, Nhlengethwa W, Newman $P A$, et al. Exploring experiences of heterosexism and coping strategies among lesbian, gay, bisexual, and transgender persons in Swaziland. Gend Dev. 2018;26(1):15-32.

43. Lee PW, Lynch I, Clayton M. Your hate won't change us! Resisting homophobic and transphobic violence as forms of patriarchal social control. Cape Town: Triangle Project; 2013.

44. Ekhuruleni Declaration. Finding practical solutions on ending violence and discrimination against persons based on sexual orientation and gender identity in Africa. Ekhuruleni; 2016.

\section{Publisher's Note}

Springer Nature remains neutral with regard to jurisdictional claims in published maps and institutional affiliations.

Ready to submit your research? Choose BMC and benefit from:

- fast, convenient online submission

- thorough peer review by experienced researchers in your field

- rapid publication on acceptance

- support for research data, including large and complex data types

- gold Open Access which fosters wider collaboration and increased citations

- maximum visibility for your research: over $100 \mathrm{M}$ website views per year

At $\mathrm{BMC}$, research is always in progress.

Learn more biomedcentral.com/submissions 